GRASAS Y ACEITES 67 (4)

October-December 2016, e160

ISSN-L: 0017-3495

doi: http://dx.doi.org/10.3989/gya.0448161

\title{
Official quality controls and the fight against fraud in the olive oil sector in Catalonia. Results 2011-2014*
}

\author{
G. Cugat ${ }^{\mathrm{a},}$ and M.R. Biel ${ }^{\mathrm{b},}$
}

\begin{abstract}
${ }^{\text {a }}$ Deputy Director-General for Agri-food Inspection and Control, Directorate-General for Food, Quality and Agri-food Industries. Ministry of Agriculture, Livestock, Fisheries and Food. Government of Catalonia

${ }^{\mathrm{b}}$ Agri-food Inspector, Subdirectorate-General for Agri-food Inspection and Control, Directorate-General for Food, Quality and Agri-food Industries, Ministry of Agriculture, Livestock, Fisheries and Food, Government of Catalonia

${ }^{\square}$ Corresponding authors: gloria.cugat@gencat.cat; rbiel@gencat.cat
\end{abstract}

Submitted: 18 April 2016; Accepted: 27 September 2016

\begin{abstract}
This article highlights the key aspects of the official control procedures concerning quality and in the fight against food fraud in the oil sector implemented in Catalonia by the Ministry for Agriculture, Livestock, Fisheries and Food of the Government of Catalonia and, more specifically, by the Subdirectorate General of Agri-food Inspection and Control. This summarized view focuses on issues related to the legality and competence framework for official controls, the goals and purpose thereof, the area's object of investigation and technical scope, the stages of the food chain at which measures are carried out, the types of inspection and control actions and the main investigation techniques. It also presents the results of the inspections, with a summary of the types of irregularities detected in the olive oil sector over the 2011-2014 period.
\end{abstract}

KEYWORDS: Food fraud; Inspection; Official control; Oil; Quality

RESUMEN: Controles oficiales de calidad y lucha contra el fraude en el sector del aceite de oliva en Cataluña. Resultados 2011-2014. En este artículo se exponen los aspectos más relevantes del control oficial en materia de calidad y lucha contra el fraude alimentario en el sector del aceite, efectuado en Cataluña por el Departamento de Agricultura, Ganadería, Pesca y Alimentación de la Generalitat de Catalunya, y en concreto, por la Subdirección General de la Inspección y Control Agroalimentario. De manera resumida se focaliza en los aspectos relacionados con el marco legal y competencial del control oficial, objetivo y finalidad del control oficial, ámbitos objeto de investigación y alcance técnico, fase de la cadena alimenticia donde se realiza, tipo de actuaciones de inspección y control y principales técnicas de investigación. Asimismo, se presentan los resultados de las inspecciones, con un resumen de los tipos de irregularidades detectadas en el sector del aceite de oliva en el período 2011-2014.

PALABRAS CLAVE: Aceite; Calidad; Control oficial; Fraude alimentario; Inspección

Citation/Cómo citar este artículo: Cugat G, Biel MR. 2016. Official quality controls and the fight against fraud in the olive oil sector in Catalonia. Results 2011-2014. Grasas Aceites 67, e160. http://dx.doi.org/10.3989/gya.0448161.

Copyright: (C2016 CSIC. This is an open-access article distributed under the terms of the Creative Commons Attribution (CC-by) Spain 3.0 License.

*This manuscript was presented at the I Workshop INSA-UB "The Universe of the Olive Oil”, in November 2015. 


\section{INTRODUCTION}

Olive oil is a key part of the Mediterranean diet and of our cuisine in general. It is a product that not only is, but also viewed by the consumer as a safe, healthy, quality food. These are some of the main reasons why it is commonly consumed as an essential product, despite the fact that it is a high-priced food on the consumer's basic shopping list. The olive oil sector has a significant presence in Catalonia, in terms of both production and consumption.

With regard to production, in Catalonia in 2014, olive trees cover some 115,044 ha and produce 181,702 tonnes of olives, the majority of which is used for the production of 36,847 tonnes of oil (Ministry of Agriculture, 2014). Nevertheless, its importance is not just economic, as it represents less than $2 \%$ of final agricultural production (FAP). It is also worth taking into account the impact of this sector in territorial and social terms, as in some areas the olive is the main crop and, accordingly, it has a huge effect on the economy and development of these areas, which have few alternatives in terms of agriculture.

From an agri-food industry viewpoint, in addition to the oil production sector, the importance of the packaging industry, using oils from other areas, and the refining industry must all be taken into account. Overall, with 199 establishments producing oils and fats and business of 1,850 million euros, the economic weight of the oils and fats sector represents $9.2 \%$ of the Catalan food industry's total turnover (Ministry of Agriculture, 2012).

What is more, some of the better quality extra virgin olive oils produced in Catalonia are sold under a quality mark from one of its protected designations of origin (PDO): Les Garrigues, Siurana, Empordà, Terra Alta and Baix Ebre-Montsià.

However, the sector is not immune to food crises, some of them unprecedented, such as the case of the denatured rapeseed oil sold in bulk at the beginning of the 1980s, which had an unquestionable impact and effect on the regulation of the sector.

Vegetables oils, and more specifically, olive oils, are highly regulated at both European and individual state levels. Few products are subject to the detailed quality-related regulations of olive oils. Examples of these include the regulation on the physical and chemical characteristics of each category of olive oil and olive-pomace oil, and even an organoleptic evaluation for virgin olive oils. Furthermore, in addition to the general food information that must be provided to consumers, olive oils have a requirement for additional information, contemplated in marketing standards such as descriptive information on the oil type, on the origin for virgin olive oils, etc.

European regulations on olive oil are constantly being revised, particularly with regard to analytical aspects (limits, new parameters for detecting adulteration, etc.).
At a Spanish level, the Technical Health Regulation on edible vegetable oils of 1983 (with subsequent amendments) is also being revised. The planned changes include the incorporation of new kinds of hitherto unauthorized oils, such as nut oils.

Olive oil is one of the top ten products most at risk for food fraud, according to the 2013 European Parliament Report on the food crisis, fraud in the food chain and the control thereof, (European Parliament, 2013) which links it with the risk of fraudulent activities such as adulteration, substitution, tampering and counterfeiting.

For all these reasons, the vegetable oil sector has always been a priority in the official control of food products and the fight against food fraud in Catalonia, carried out by the Ministry for Agriculture, Livestock, Fisheries and Food of the Government of Catalonia.

The key mission of this official control is to protect the economic interests of actors in the agri-food chain (producers, processers and consumers) with regard to products' conformity in terms of quality and to guarantee transparency and fair competition in commercial transactions.

The main aspects of official control dealt with in this article are its legal and competence framework, goals and purposes, areas under investigation and technical scope, the stages of the food chain at which measures are carried out, the types of inspection and control actions and the main investigation techniques (Graph 1).

The results of the inspections are also provided, with a summary of the irregularities detected in the olive oil sector over the 2011-2014 periods.

The chief goal of the official control of the quality of agri-food products and the fight against fraud in the oil sector in Catalonia is to verify compliance with quality standards by the oils produced and/ or shipped by the agri-food business encompassed within its territorial scope.

Official control of food is an obligation of Member States of the European Union. These controls must be organized and brought into line in a standardised manner within the framework of European regulations, and the European Commission periodically audits control authorities to ensure that this is so.

\section{MATERIALS AND METHODS}

\subsection{Official control of food quality and the fight against fraud}

\subsubsection{The legal framework for official control}

Regulation EC No. 882/2004 (EC, 2004), establishes the bases for official food controls and regulates the obligations of Members States to monitor the market and perform regular risk-based controls, 


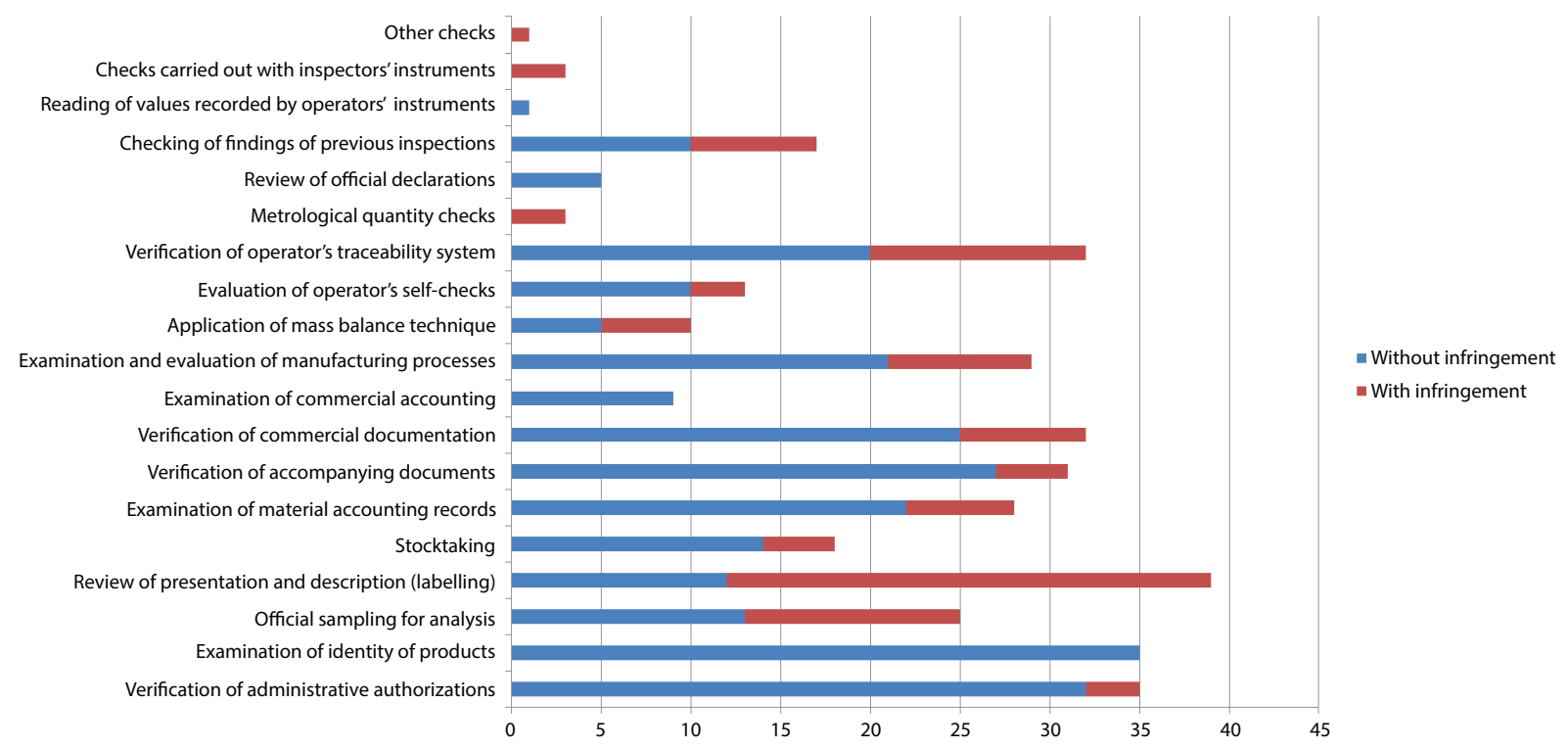

GRAPH 1. Types of control performed (2011-2014).

the organization of controls, official samples and analysis, crisis management, official assistance and cooperation, control plans, audits, enforcement measures for non-compliance, penalties, etc.

The Defence of Food Quality Act 28/2015 (BOE, 2015), provides the basic Spain-wide regulations in defence of food quality and the penalty system.

By means of the Agri-food Quality Act 14/2003 (CatalanLaw, 2003), the Government of Cataloniaregulates the main applicable aspects of the European mandate on official control, and establishes the bases for ensuring agri-food quality, regulates the obligations of food business operators, inspection rights and duties, responsibility for infringements, precautionary measures, penalty system, etc.

Lastly, one should not forget Regulation, EEC 2568/91 (EC, 1991) on the characteristics of olive oil and olive-residue oil and on the relevant methods of analysis, which also regulates specific aspects of the quality control of olive oils and olive-residue oils. Amongst other things, it is worth noting that the Regulation establishes that conformity checks must be carried out selectively, based on a risk analysis, and also sets criteria to assess the risk, such as:

a. The category of oil, the period of production, the price of oils, the country of origin, the country of destination, etc.

b. The position of the operators in the marketing chain, the volume and/or value marketed, etc.

c. Findings made during previous checks (number and type of defects, etc.)

d. The reliability of operators' quality assurance systems or self-checking systems e. The place where the check is carried out: first point of Union entry/exit, production, packaging, sale to final consumer, etc.

It also establishes that, in the case of non-compliance, penalties must be effective, proportionate and dissuasive.

\subsubsection{Competence framework of official control}

In Catalonia, the Government of Catalonia (Generalitat de Catalunya) has exclusive competence over the quality and traceability of agricultural and livestock products in the fight against fraud in agrifood production and sales.

More specifically, the Ministry of Agriculture, Livestock, Fisheries and Food's (MALFF) Directorate-General for Food, Quality and Agrifood Industries (DGFQAI) is the competent authority in the fields of food quality and the fight against fraud.

Inspection and control actions carried out by the Subdirectorate General of Agri-food Inspection and Control fall within Spain's National Plan for Official Control of the Food Chain (Plan Nacional de Control Oficial de la Cadena Alimentaria, PNCOCA), which is multi-year in nature (2011-2015 and 2016-2020) and, in particular, are included in the Programme for the Official Food Quality Control System.

\subsubsection{The purpose of the inspections}

The main purpose of the fraud inspections is to detect fraud, deception, counterfeiting, adulteration, unauthorized or banned practices or any other 
type of infringement of quality regulations that may involve economic harm or prejudice for any actor in the food chain.

It is also important to identify the food business operator responsible for the possible infringements.

\subsubsection{Main aspects under investigation}

The inspection checks focus mainly on food products, and on the following aspects:

a. Product properties: nature, identity, essential qualities, composition, origin and provenance, etc.

b. Identity and activity of the agri-food business operators

c. Quantity of product placed on sale (metrological control)

d. Proper use of designations of origin or other official quality marks

Excluded from the definition of food products are certain categories such as seeds, medicines, animal health products, plant health products, medicated feedstuffs, infant and dietetic foods, cosmetics, tobacco, live animals and plants before harvesting, etc.

Official control of food quality excludes the following aspects, which are included within the scope of the functions of other public administrations:

a. Health-related aspects governed by rules on health and hygiene, veterinary matters or the physical safety of persons or animals

b. Environmental control

c. Tax control

d. Control of aid or grants from the public administrations

e. Control of facilities and equipment itself

f. Controls associated with the certification of food business operators or the classification of products (PDO or other quality marks)

The technical scope of investigations to detect and determine food fraud includes checks on:

a. Raw materials and other items used in the production or manufacture of the products and their placing on the market.

b. Conditions of the production process and of the placing on the market of food products that impact upon their quality

c. Presentation, denomination or other information in the labelling, packaging, advertizing or documentation of the traceability system

\subsubsection{Stage of the food chain subject to inspection}

Official inspections to control food quality and to fight against fraud are carried out at source and therefore at the facilities or establishments where the food products are produced, stored and/or shipped for introduction into the sales circuit.

In the olive oil sector, inspections are usually carried out in oil production facilities, bulk oil storage and packaging and distribution installations, as well as at oil refining plants and raw olive-residue oil extraction plants.

In general, direct-end consumer points of sale (retail and distance selling, restaurants, mass caterers, wholesale markets. etc.) are excluded from these inspections, as they fall within the scope of the powers of other administrations.

\subsubsection{Actions in the fight against fraud}

Inspection and control actions carried out by the Subdirectorate General can be broken down into three types:

2.1.6.1. Inspections programmed in advance in the annual General Inspection Plan at companies selected by means of risk analysis.

2.1.6.2. Unplanned, non-programmed inspections arising from unexpected events or suspected infringements such as:

a. Complaints from private individuals, food company operators, associations, PDO regulating boards, etc.

b. Supported request from other control authorities who have checked or have evidence of irregularities that affect food company operators falling within this territorial scope, within the framework of the assistance, collaboration and cooperation of competent official control authorities.

c. other information (press, investigations, etc.)

2.1.6.3. Exploratory controls. These are controls rather than inspections, and are carried out on a systematic basis to categorize food companies on the basis of the risk elements evaluated (activity, selfchecks, traceability, etc.).

\subsubsection{Characteristics of inspections in the fight against fraud}

Some of the key characteristics of fraud inspections are:

a. An inspection report, to officially place on record the facts and proof or evidence of non-compliance.

b. Use of investigation and audit methodology, based on specific techniques (physical checks, identification and documentation reviews)

c. Unannounced inspections of food company operators 
d. Repressive in nature, such that the detection of infringement will entail the opening of penalty proceedings

e. In the case of serious non-compliance, inspectors are entitled to adopt precautionary measures, such as the immobilization of products or labels, ceasing of activities, recall of products from the market, a ban on advertising, etc.

\subsection{Inspection techniques}

The techniques used in inspections in the fight against fraud include physical checks, product identification checks and the review of documentation on the product, particularly the documentation making up the traceability system.

By way of example, some of the most frequently used techniques in inspections of the oil sector are:

\subsubsection{Physical and product identification checks}

a. Examination of the identity of the products in stock at the facilities (type of oils, ancillary products, additives, etc.).

b. Examination and evaluation of production, packaging, storage, etc. processes.

c. Sampling of products for official analysis. Due to the wide-ranging nature of the regulations on the physical, chemical and organoleptic properties of oils, this is a key check, and one that needs to be done in accordance with the official methodology for sample taking.

d. A review of product presentation and description, chiefly the packaging conditions, to prevent the bulk sale of olive oils to the end consumer and verification of labelling, including justification of included information to evaluate its truthfulness.

e. Gauging of products in stock (stocktaking) to apply the mass balance technique, particularly in the case of the co-existence of different types and categories of oils, quality marks, etc.

f. Reading of values recorded by the operator's instruments, for example, the extraction temperature.

g. Checks carried out by the inspection service's own instruments, such as metrological or quantity controls to check the actual contents of the container.

\subsubsection{Documentation checks}

a. Verification of administrative authorizations for the food company operator's activity

b. Verification of documents accompanying the products (goods delivery notes, CMR, etc.) and commercial documentation (invoices, contracts, etc.) c. Examination of material accounting records (entries, exits, production, treatment, byproducts, etc.)

d. Examination of commercial and financial accounting

e. Verification of operator's traceability system

f. Evaluation of operator's self-checks

g. Review of official compulsory declarations

\subsection{Inspection findings}

Before entering into detail, it should be borne in mind that this article is not intended to be a quantitative summary of the official control actions carried out in the oil sector. This type of information on official controls, with a breakdown of the number of inspections and controls, samples taken, quantities immobilized, number of irregularities detected, etc. is presented annually in the findings reports, which are available on the Ministry web page on official controls in the fight against fraud: http://agricultura.gencat. cat/es/ambits/alimentacio/lluita-frau-alimentari/.

The irregularities described have been established during inspections, in other words during the inspection stage and not the resolved penalty proceedings. As is well known, the penalty proceedings weigh up the allegations and the counter-analysis by the company responsible for the infringements and may, in some cases, entail the dismissal or shelving of certain irregularities detected during the inspection stage. Besides, the inspections are performed on the basis of a risk analysis, with companies which are selected by taking into account a range of risk factors analyzed, such that inspections are targeted based on the appreciation of a higher risk of fraud. This gives a greater probability of detecting infringements. Finally, these findings should not, therefore, be regarded as a representative image of the oil sector in Catalonia.

\section{RESULTS}

Below are the results of the quality control and anti-fraud inspections, with a summary by type of irregularity detected in the oil sector during the 2011-2014 period and the distribution of controls with irregularities (Graph 2).

\subsection{Counterfeiting of products}

- Production and placing oils on the market with a protected designation of origin (PDO) made from olives from outside the production area

- Improper use of a PDO's name in labelling and advertising for oils not entitled to the PDO

- Production and placing oils on the market with more highly valued sales descriptions that do not comply with the product's definition 


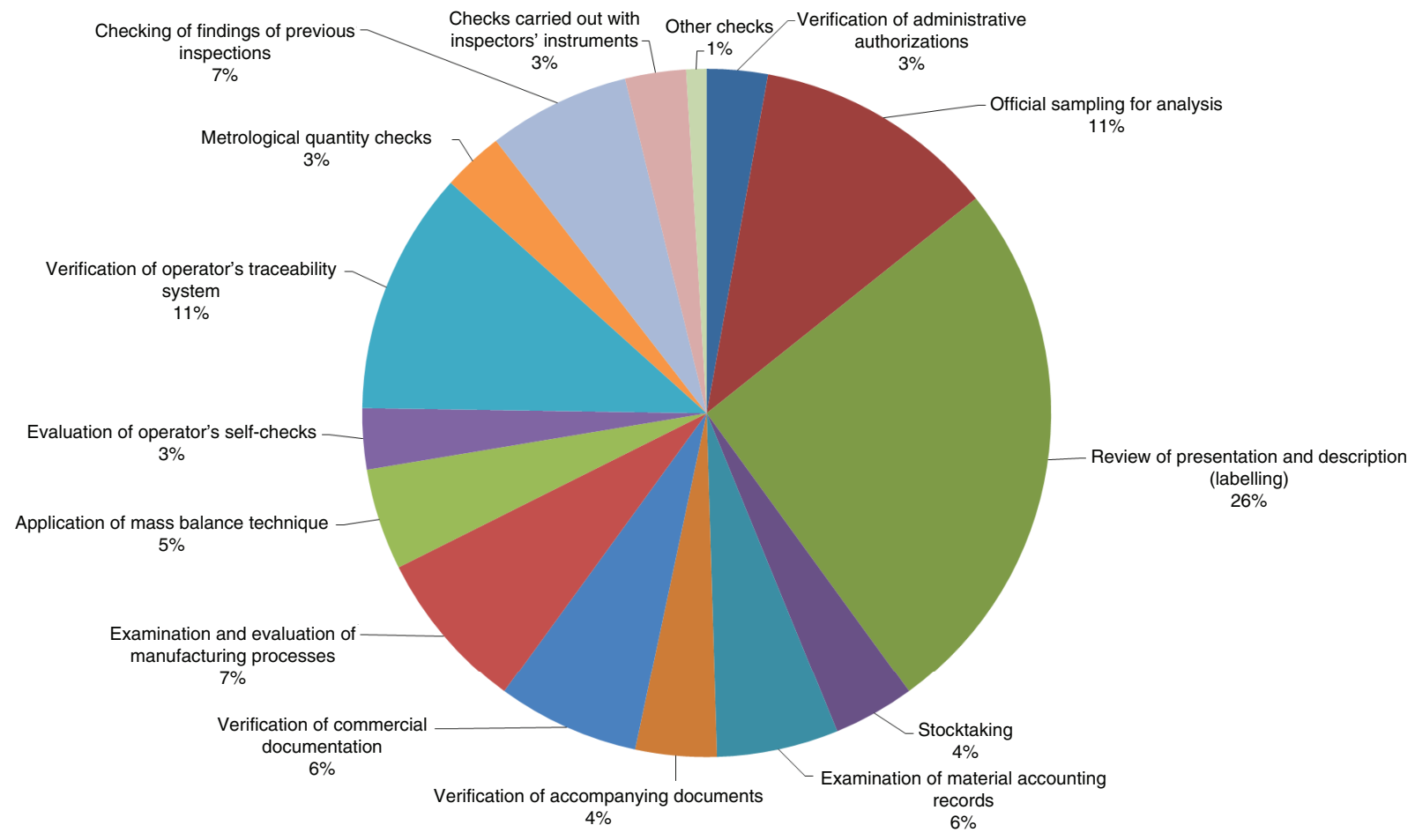

GRAPH 2. Distribution of controls with irregularities (2011-2014).

or that do not meet the stipulated analytical characteristics

\subsection{Counterfeiting in composition, purity and quality}

\subsubsection{Olive oils intended for the final consumer or mass caterers}

- Organoleptic evaluation (median defects, fruity median) of extra virgin olive oil (EVOO) and virgin olive oil (VOO) associated with lower categories of olive oil: VOO and lampante olive oil (LOO)

- Peroxide index in VOO associated with LOO (indicative parameter of oil quality)

- Stigmastadiene in VOO (indicative parameter of purity, an indication of the presence of refined vegetable oils)

- Fraud in the trade of EVOO (blending with refined vegetable oils)

- Fraudulent production of olive oils composed of refined and virgin olive oils, on the basis of nonconforming refined olive oils (ROO) detected by checking the documentation of traceability of the components of the mixture oils

- Production of EVOO with unauthorized colors additive (E175 gold color)

\subsubsection{Lampante olive oils for refining}

- Non-conformity with the definition of this kind of oil set out in the Regulation (UE), because nonconforming oil detected had not been obtained from the fruit of the olive tree solely by mechanical or other physical means without alterations in the oil. It included tank remains, muddy sediments, oils from plants of extraction of crude olive pomace oil and other kinds of oils

- Non-conformity with the chemical characteristics stipulated for this category of oil. Outof-range parameters: waxes, erythrodiol and uvaol, ECN42 difference, brassicasterol, betasitosterol, delta-7-stigmastenol, campesterol, total transoleic isomers and total translinoleic + translinolenic isomers. All of these are purity parameters and an indication of blending with other types of oils (olive-pomace oil and seed oils)

- Fraudulent production of ROO from nonconforming LOO

\subsubsection{Refined seed oils}

- Refined seed oils with unauthorized colors (E160 beta-carotene). In certain cases, the presence of color additives was detected in refined seed oils to simulate olive oils 


\subsection{Presentation and labelling defects}

\subsubsection{Presentation}

- Placing olive oil on sale to final consumers in 25-litre containers

- Placing unpackaged olive oil on sale to final consumer in containers not sealed and not labelled or unlabelled containers.

\subsubsection{Misleading or deceptive labelling}

- Misleading sales descriptions associated with more highly valued categories

- Use of protected designation of origins reserved for oils with PDO

- Mentions of organic and integrated production in conventional oils

- False origin of olives or oil

- False olive variety

- Mention of 'cold extraction' or 'first cold pressing' production methods

- In olive pomace oil, the ingredient "virgin olive oil" is highlighted and the designation "olive pomace oil" is not easily visible or clearly legible. This presentation of food information is misleading to the consumer about the type of oil

- Indication of a maximum absorbance value $\left(\mathrm{K}_{270}=\right.$ $0,10)$ on the label, and the analyzed result was higher $\left(\mathbf{K}_{270}=0,11\right)$ than the indicated value

- Mention of 'superior quality', 'natural', 'extra', etc., associated with more highly-valued products, in lower categories of olive oil

\subsubsection{Misleading or deceptive labelling of other oils or products}

- Indicating 'extra virgin olive oil' as an ingredient when using other oil

- Indicating 'oil' in products that are a blend of oils and fats

\subsubsection{Lack of supporting documentation for labelling information}

- Origin

- Variety

- Production method

- Fruity oil

\subsubsection{Omissions or incomplete information in labelling}

- Lack of information describing the category of olive oil

- Lack of obligatory information on designation of origin (EVOO and VOO)

- Lack of information on special storage conditions
- Lack of or incomplete mention of business name

- Lack of or incomplete mention of address of food business operator

- Lack of information on net quantity

\subsubsection{Improper information}

- Indication of origin in olive oils composed of refined and virgin olive oils (EVOO and VOO only)

- Indication of designation of origin using nonregulatory toponyms $(\mathrm{EU}$, Member State, third country, PDO only)

- Incorrect information about words preceding date of minimum durability

- Incorrect designation of ingredients

- Information suggesting that the oil has special characteristics different to those of similar oils

- Incorrect indication of acidity (failure to indicate other obligatory parameters)

\subsubsection{Legibility of labelling}

- Illegible compulsory information (font size, color contrast, etc.)

- Indication of net quantity with a figure below the minimum stipulated height

\subsection{Fraud with regard to actual content}

- Fraud with regard to actual content (volume) declared on label

- Lack of supporting documentation on selfchecks of actual content

\subsection{Mass balance technique}

- Balances in fraud situation due to amount and category of oils. This often involves the replacement of a more highly valued category of oil by another of lesser commercial value

- Balances in irregular situation by reason of quantities and categories of oils

\subsection{Traceability}

- Lack of traceability in products

- Lack of production registers or on some other part of the product traceability assurance system

- Lack of a documented quality plan

- Accounting records on products and transactions not updated

- Sales or accompanying documentation: Issuing of invoices or goods delivery notes without indication of sales description or with incorrect or misleading information

- Deficient or insufficient traceability documentation 


\section{CONCLUSIONS}

The irregularities detected reveal the importance of official controls and the need to remain vigilant in the fight against fraud so as not to undermine consumer confidence in this cherished food product and to defend the interests of the majority of oil sector companies, which work in compliance with applicable regulations.

One preventative measure to improve oil quality involves improving the information given to and the training of those associated with the sector, with regard to both the production of olives and the production and placing of olive oil on the market.

For this reason, the Subdirectorate General for Agri-food Inspection and Control provides information on vegetable oils in a specific section of the website of the Ministry of Agriculture, Livestock, Fisheries and Food http://agricultura.gencat.cat/ca/ ambits/alimentacio/, to help food company operators in the sector comply with the applicable legislation and ensure the production of quality products, as well as to help consumers understand the types of oils placed on the market and the food information available. This section is broken down into the subsections included in Table 1.

Information is also provided on official controls and the fight against fraud at http://agricultura. gencat.cat/es/ambits/alimentacio/lluita-frau-alimentari/, with details on the actions carried out and their findings, planning, regulation, alerts, and so on .

This inspection unit also takes part in training and information programmes for the oil production sector.

TABLE 1. Section of MALFF website on vegetable oils. http://agricultura.gencat.cat/ca/ambits/alimentacio/

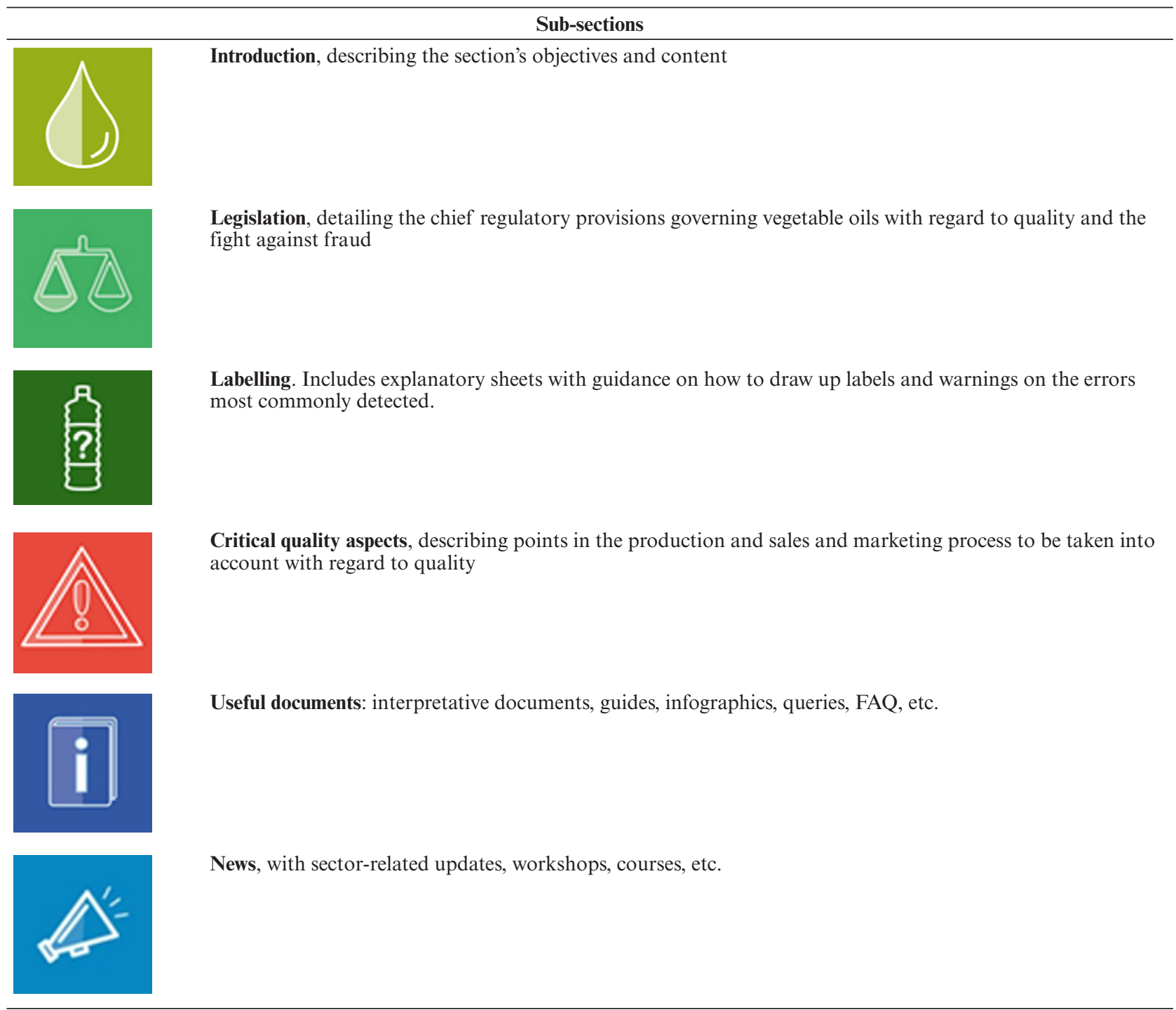


Finally, we would note that the publication of this information on the findings of official controls constitutes an exercise in transparency on the part of the Administration and also seeks to provide a contribution to information for researchers, inspectors and technicians working in the olive oil sector and for the development of new techniques, analytical or not, to improve the quality of olive oils and to fight against food fraud in this sector.

\section{ACKNOWLEDGMENTS}

We would like to thank all those working in the Subdirectorate General for Agri-food Inspection and Control of the Government of Catalonia's Ministry of Agriculture, Livestock, Fisheries and Food, and particularly all the agri-food inspectors, for the contribution they make, day in, day out, to the fight against fraud.

And also the organisation of the I Annual INSA Workshop: The Olive Oil World, held at the
UB Food and Nutrition Torribera Campus on 11 November 2015.

\section{REFERENCES}

Ministry of Agriculture, 2014. Livestock, Fisheries and Food. Secretariat General. Agriculture of Food Studies and Outlook. Agricultural crop areas and productions.

Ministry of Agriculture, 2012. Livestock, Fisheries and Food. Report on the agri-food industry, distribution and consumption in Catalonia.

European Parliament, 2013. Report on the food crisis, fraud in the food chain and the control thereof (2013/2091 (INI)) 4-12-2103.

EC, 2004. Regulation (EC) No 882/2004 of the European Parliament and of the Council of 29 April 2004 on official controls performed to ensure the verification of compliance with feed and food law, animal health and animal welfare rules (OJEU L165 30-04-2004)

BOE, 2015. Spanish Law 28/2015, of 30 July, for food quality protection. Boletin Oficial del Estado. BOE 182 31-07-2015.

Catalan Law 14/2003, of 13 June, on agri-food quality (DOGC 3915 1-07-2003).

EC, 1991. Commission Regulation (EC) No 2568/91 of 11 July 1991 on the characteristics of olive oil and olive-residue oil and on the relevant methods of analysis (OJ L248 5-09-1991). 